\title{
The discourse of liberation: Frames used in characterising the gay liberation movement in two South African newspapers
}

\author{
Lauren Danger Mongie \\ Department of General Linguistics, Stellenbosch University, Private Bag X1, 7602 Matieland, South Africa \\ E-mail: laurenm@sun.ac.za
}

\begin{abstract}
This article reports on the quantitative findings of a study that straddles the applied linguistic field of critical discourse analysis and a sociolinguistic field recently referred to as "queer linguistics". Drawing on a quantitative method of analysis, the study investigates the linguistic framing of LGBT mobilisation in two South African newspapers, City Press and the Mail \& Guardian, across a period of almost 30 years. It aims to identify the characteristics of the discourses that topicalise the gay ${ }^{1}$ liberation movement in order to investigate the ways in which linguistic means have been used in articulating the need and the right to liberation and how arguments against the gay liberation movement have been framed, reframed and counterframed in South African media. The study's findings revealed that a number of frames, including 'liberation', 'rights' and 'victimisation', reoccurred in the framing of arguments for the gay liberation movement throughout the data collection period in both corpora, and while City Press primarily used these frames to express anti-gay sentiments, the Mail \& Guardian primarily used these frames to express pro-gay sentiments. The findings also revealed that a number of frames, including 'religion', 'morality' and 'nature', reoccurred in the framing of arguments against the gay liberation movement, and again while City Press primarily used these frames to express anti-gay sentiments, the Mail \& Guardian primarily used these frames to express pro-gay sentiments. Finally, the findings revealed that a single frame such as "religion" was typically used to express both pro- and anti-gay sentiments, bringing to light the important role that counterframing plays in bringing about social transformation.
\end{abstract}

Keywords: framing, gay liberation, media discourse, counterframing

\section{Introduction}

Almost 20 years after protection from discrimination on the basis of sexual orientation was included in South Africa's constitution, homophobic discourse and violence remains

\footnotetext{
${ }^{1}$ The word "gay" is used as a hypernym in this article as this is a reflection of the way in which the liberation movement was typically topicalised in the data.
} 
disturbingly prevalent. Moreover, South Africa's constitutional recognition of $\mathrm{LGBT}^{2}$ rights stands in stark contrast to the laws and sentiments of both its neighbouring countries and the rest of Africa, which calls into question the cause of what some have termed the "surprising success" (Gevisser 1995: 78) of South Africa's gay liberation movement, as well as the extent to which the movement can be considered "successful" and "complete".

This article reports on the findings of a larger doctoral project (Mongie 2013) that investigated the linguistic strategies employed by two South African newspapers to represent the South African gay liberation movement from the early 1980s up to 2006. Drawing on both quantitative and qualitative methods of analysis, the article aims to identify the linguistic characteristics of the discourse identified here as "gay liberation discourse", which topicalises the gay liberation movement, in order to address the following research questions ${ }^{3}$ :

(i) What types of micro- and macro-structures characterise the discursive (re)production of the ideologies of actors for and against the gay liberation movement in South Africa after 1982?; and

(ii) Which types of frames are used in the (re)production and/or challenge of homophobic ideologies in reports topicalising the gay liberation movement in South Africa?

The purpose of answering these research questions is to make sense of the processes involved in bringing about social change through discursive mobilisation, and to contribute to the understanding of the linguistic forces that shaped South Africa's gay liberation movement.

\section{Rationale}

My selection of mass media data and Critical Discourse Analysis (CDA) theory and methodology was motivated by the fact that, considering various forms of public and institutional discourse available to social movement actors, the mass media is widely acknowledged to be the most influential in terms of ideological socialisation and effectuating social change (Van Dijk 1995: 22). This can be ascribed to (i) the "general audience" nature of the media (Gamson 1995: 86), which provides social movement actors with the opportunity to mobilise existing supporters, garner bystander support, and provide counterframes to the opposition; (ii) the fact that movement actors assume that the media is influential, and thus assess movement success in terms of media coverage; and (iii) the fact that the media produces social reality in the sense that it "both signals and spreads social change" (Gamson 2004: 243).

Additionally, the targets of a social movement often ignore its claims and demands until the movement receives a certain amount of media coverage, at which time it starts to be considered a part of the public agenda (Gamson and Wolfsfeld 1993: 116), which further highlights the need for interrogating these processes (Van Dijk 1995: 22). Finally, the media plays a particularly prominent role in the construction of attitudes towards homosexuality, as many individuals have no first-hand experience with a gay or lesbian person and the taboo nature of the topic means that it is often silenced among traditional sources of knowledge such as friends, family, churches, and educational institutions (Calzo and Ward 2009: 180).

\footnotetext{
${ }^{2}$ While the 2013 study collected data on the discursive construction of transgenderism, it did not report on the findings as the scope of the thesis did not allow for it.

${ }^{3}$ See Mongie (2013: 3) for the full set of research questions.
} 
As is the case with many powerless minority groups, media coverage of gay and lesbian South Africans has largely been characterised by silence, sensationalism, and the perpetuation of stereotypes (Cilliers 2007: 334). Gevisser (1995: 77) remarks on this, pointing out that sensationalism has characterised media coverage of homosexuality since the 1950s, and that homosexuals have variously been portrayed as child molesters, drag queens, over-sexed hedonists, and AIDS victims. Although the constitutional reforms of the 1990s resulted in increased media coverage of gay and lesbian issues, a recent study revealed that South African media coverage of homosexuality continues to be characterised by "scandals, negative images, and stereotypes" (Ndlovu 2006: 9).

Media coverage of gay and lesbian issues has undoubtedly improved in both volume and content in the years following the decriminalisation of homosexuality in South Africa in 1998. The increased media attention resulting from the constitutional rights afforded to gay and lesbian South Africans has contributed to the visibility of the gay and lesbian community, placing sexual orientation on the public agenda. On the one hand this has provided positive recognition; on the other hand this has increased the likelihood of homophobic victimisation (Reid and Dirsuweit 2002: 103).

The nature of the data that forms the focus of this research made queer linguistic theory and methodology - an area of study that problematises the role of language in reproducing heteronormative attitudes - an obvious choice. Further, the data also lent itself to the combination of quantitative and qualitative analyses that has come to characterise queer linguistics (Milani 2013: 4).

\section{Theoretical framework}

The project takes CDA, particularly its applications in considering features and functions of media discourses, as its primary theoretical framework. It follows the analytic methodology suggested by Van Dijk (1991) in considering issues of language and power, the ways in which individuals use varying degrees of media access in order to express their ideologically-based opinions through textual devices in news media, and the ways in which the access of elites to media is drawn on to support and give credence to particular ideologies. I selected Van Dijk's theoretical and methodological framework for this study as I found his modelling of the process through which public discourses are internalised into personal ideology before being externalised as personal discourse to be useful to the study's investigation of the interface between individual ideologies and the media's representation of South Africa's gay liberation movement. Also, the extensive set of analytical units given in Van Dijk's (1991, 1993, 1995, $1998,2003)$ work was found to be helpful in identifying the micro- and macro-structures that characterised arguments for and against gay rights in the selected news articles.

In order to provide additional theoretical insight, I supplemented Van Dijk's methodology with several concepts from the fields of Social Movement Theory and Collective Action Framing (CAF) in an attempt to make sense of the strategy in which movement actors make use of emphasis framing (Druckman 2001: 230) in order to simplify a social issue by focusing on a small subset of aspects of the issue in question. In CAF, this is done in order to (i) articulate grievances and goals in a meaningful and integrated way, (ii) manufacture consensus and mobilisation among (potential) constituents (Snow and Benford 1992: 137), and (iii) demobilise opponents (Snow and Benford 2000: 614). 
The aim of implementing frames in these ways is ultimately to bring about social change, the most dramatic of which is known as "frame transformation", which refers to "attempts at reconstructing and overturning widely accepted meanings, understandings, beliefs and values by reframing issues in new ways" (Snow, Burke Rochford Jr., Worden and Benford 1986: 473). Frame transformation is typically achieved with the help of reframing or counterframing, and is typically required when the goals of the social movement are not connected with widely held societal values, and new values need to be created (Snow and Benford 2000: 617). Although it has largely been ignored by the literature (Chong and Druckman 2013: 1), counterframing is a natural part of the way in which contested attitudes are dealt with in the media, and is an important source of attitude change. Further, research shows that the effects of counterframes are influenced by the order in which the frames appear, the amount of times that the counterframe is repeated, and the amount of time that passes between frames (Chong and Druckman 2013: 3). This last aspect of counterframing is important as the literature indicates that frames decay over time, and that the rate of decay is affected by the strength or weakness of the attitude in question.

Theorists who focus on the role of collective action frames in social movements (cf. Tarrow 1988; Gamson 1995, 2004; Snow and Benford 1988, 2000) agree that public discourse plays a critical role in determining the outcome of a social movement, as the "collectivity" of collective action frames rests on the sharing of frames among elites, the media, and members of the public. Public discourse is of particular importance for the (re)production of the perception of injustice, as the first step towards achieving social change is to publicly share knowledge of and indignation about a perceived injustice with supporters and challengers (Tarrow 1988: 111).

\section{Methodology}

Based on their circulation demographics, two local South African weekly newspapers, City Press and the Mail \& Guardian, were screened in order to identify print-news articles written by journalists and letters to the editor written by readers that made reference to same-sex attraction. City Press was selected for analysis due to its status as one of South Africa's most widely distributed weekly newspapers (with the third highest circulation of all newspapers in the country), as well as its predominantly black readership. The Mail \& Guardian was selected for analysis due to its reputation for strong, informed criticism of the government, which it gained in the run-up to the democratic elections in 1994. In the years following the country's transition to democracy, the Mail \& Guardian has maintained its reputation for investigative reporting and political analysis, and independent, liberal positioning that distinguishes it somewhat from the more conservative positioning of City Press.

Included in the discourse selected for analysis are not only newspaper items that were mainly supportive of accepting same-sex attraction and gaining gay rights (hereafter known as "progay publications"4) but also voices that mainly protested against the acceptance of same-sex attraction and the acknowledgement of such rights (hereafter known as "anti-gay publications"). As the newspapers selected for analysis did not have any electronic archives, the full complement of published items topicalising same-sex attraction directly and indirectly

\footnotetext{
${ }^{4}$ While the terms "pro-gay" and "anti-gay" may appear to imply a dichotomy, there is in fact a continuum; such a dichotomy was helpful in the summary, but is corrected in the qualitative analysis presented in the original study. Further, I prefer these terms over, for example, "gay (in)tolerant" and "gay (un)sympathetic" as such terms imply that acceptance of same-sex attraction requires tolerance or sympathy rather than equal status.
} 
were hand-collected as two (non-electronic) corpora. This was done in order to perform two analytic exercises: first, the content of the full data-set was "tagged" and categorised according to the textual nature of the newspaper item and the kinds of frames used in its presentation; second, a number of articles and letters were selected from the corpora for detailed qualitative analysis ${ }^{5}$ that would illustrate the use of the various strategies and frames found to characterise the discourse. This article will report on the quantitative study that formed the basis of the more detailed analysis as this analysis provides valuable insights into the nature of the arguments that underscored both pro- and anti-gay discourse at various points of the gay liberation movement, the ways in which individual frames were drawn on in both pro- and anti-gay arguments, and the ways in which these arguments changed over time in accordance with the country's broader liberation movement.

An overview of the full data-set was conducted in order to quantitatively establish and record a number of things interesting to the investigation. A summary of the full set of items was captured in Excel sheet format, including the following information:

(i) the general positioning of the article, i.e. an indication of writer sentiment;

(ii) the macropropositional content of the article;

(iii) the identification of master frames and additional frames

The summary of specific publications across 24 years according to the above set of features and several others was done to assist in identifying patterns, trends and editorial practices typically used in the media representations that were part of the same-sex attraction discourse of the period. Certainly, categories such as these used in the summary are often given in the form of simple binary distinctions which may appear to ignore the complexity of such a large volume of publications. In fact, most do present on a spectrum of bias, prejudice and (in)tolerance. A review of the macro- and micropropositional content of each publication made a Likert-type classification possible, which was used for identifying trends in the data that could not be identified without statistical analysis.

\section{Strength in numbers - Counting frames in LGBT news reports}

\subsection{Distribution of publications expressing pro-gay and anti-gay sentiments}

To assess the newspapers' ideological stances regarding gay liberation, two indicators were used, namely explicit journalistic positioning and the frequency at which each newspaper carried material that topicalised same-sex attraction. A quantitative breakdown of City Press and Mail \& Guardian publications by type and positioning shows that City Press published a total of 234 items in the time period between 11 April 1982 and 15 October 2006 (1279 weeks / 24.5 years), which amounts to considerably less than 1 item $(0.18)$ in this discourse per week; of these, 39\% were used to express pro-gay sentiments, 35\% were used to express anti-gay sentiments, and $26 \%$ had no clear positions. The Mail \& Guardian published a total of 550 items in a similar time period, between 9 May 1986 and 21 December 2006 (1076 weeks / 20.5 years) which, although publishing more items in a period four years shorter than that of City Press, still amounts to less than 1 item (0.51) per week; of these, 74\% were used to express progay sentiments, $8 \%$ were used to express anti-gay sentiments, and $18 \%$ had no clear positions.

\footnotetext{
${ }^{5}$ See Mongie (2013: 186-257) for the results of the detailed analyses.
} 
Of the 234 news items that make up the City Press corpus, the genre in 79\% was that of regular articles (of which $40 \%$ were pro-gay and $29 \%{ }^{6}$ were anti-gay). Of the 550 news items that make up the Mail \& Guardian corpus, the genre in $67 \%$ was that of articles (of which $75 \%$ were progay and $4 \%$ were anti-gay), and in $17 \%$ the genre was letters to the editor (of which $72 \%$ were pro-gay and $28 \%$ were anti-gay). These figures indicate that the Mail \& Guardian topicalised same-sex attraction more frequently and in a more pro-gay way than City Press during the covered period; the figures further indicate that in both corpora anti-gay sentiments were articulated more frequently in letters to the editor than in articles.

Figure 1 represents in graph form the differences in the number of pro-gay and anti-gay publications across the given period of time (1982-2006):

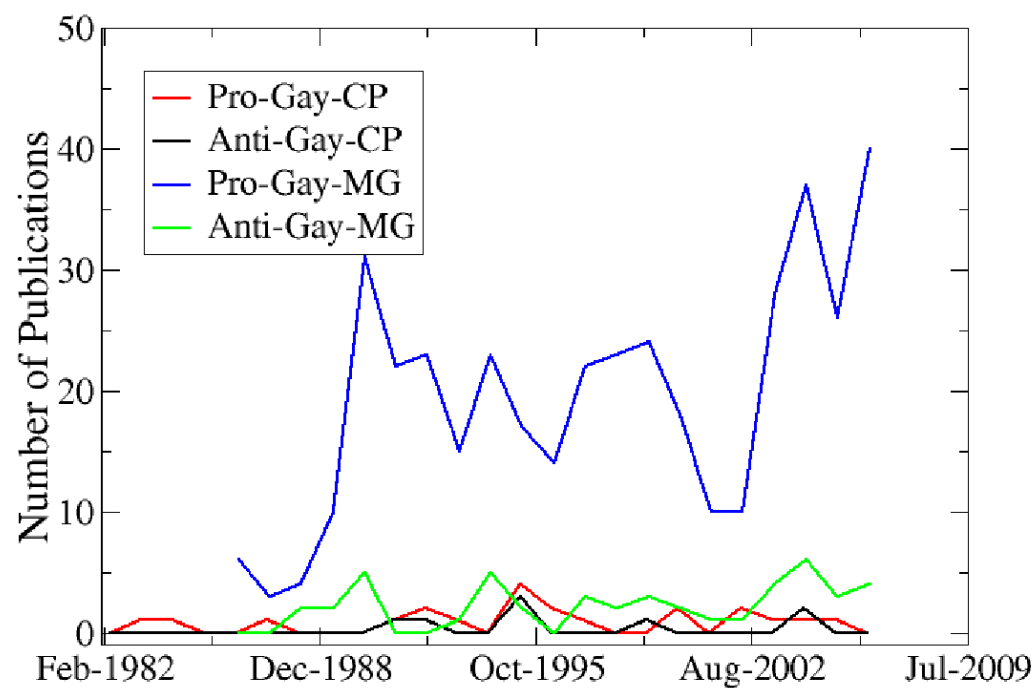

Figure 1. Distribution of pro- and anti-gay sentiments in both corpora

In this figure, it is clear that one of the main differences between the discourses of City Press and the Mail \& Guardian is the way in which the newspapers position themselves ideologically, with the City Press corpus consisting of 39\% pro-gay publications and $29 \%$ anti-gay publications, and the Mail \& Guardian corpus consisting of $74 \%$ pro-gay publications and $8 \%$ anti-gay publications. As is illustrated in this figure, the City Press data shows a pattern across the full data collection period in which the number of articles and letters with a master frame conveying an anti-gay stance is more or less equal to the number conveying a pro-gay stance. By contrast, the graph demonstrates that the pattern in the Mail \& Guardian was to publish considerably more pro-gay and gay-supportive material. The graph also demonstrates the fact that pro-gay publications outweighed anti-gay publications in the City Press corpus from the beginning of the data collection period until 2001, after which both neutral and anti-gay publications outweighed pro-gay publications, while pro-gay publications outweighed anti-gay publications throughout the Mail \& Guardian corpus.

Figure 1 also gives a visual image of the cyclical nature of discourses topicalising same-sex attraction, showing how years of high frequency of publications are interspersed with years of

\footnotetext{
${ }^{6}$ Where these figures do not add up to $100 \%$, the remainder of the items were categorised as neutral in positioning, with "neutral" referring to both unbiased sentiments and publications in which pro-gay and anti-gay sentiments were considered to balance each other out.
} 
low frequency of publications. Three points of high frequency of publications with a same-sex attraction theme can be identified, namely (i) the period shortly after the unbanning of opposition movements in 1990; (ii) the period following South Africa's first democratic elections in 1994; and (iii) the period between 2002 and 2006 which preceded the legalisation of same-sex marriage. The latter was the period in which same-sex attraction was topicalised the most in both corpora, in that across the 24 -year span $43 \%$ of the total City Press publications and $36 \%$ of the total Mail $\&$ Guardian publications on this theme were printed. The fact that these points of high frequency overlap with times of significant transitional events corresponds with social movement theorists' (cf. Tarrow 1988, Gamson 1995, Snow and Benford 2000) claims that transitioning from a nondemocratic system to a democratic one provides increased political opportunities for minority groups to place their concerns on the public agenda.

\subsection{Commonly used frames}

A review of the data summarised quantitatively enabled the identification of 14 themes: the tolerance or intolerance of same-sex attraction (hereafter referred to as "(in)tolerance frames"); religious motivations for the (in)tolerance of same-sex attraction (hereafter referred to as "religion frames"); South Africa's broader liberation movement and the values that are attributed to the "New South Africa" (hereafter referred to as "liberation frames"); the recognition (or lack thereof) of human rights (hereafter referred to as "rights frames") the legal issues faced by members of the LGBT community (hereafter referred to as "legal frames"); the morality (or lack thereof) of same-sex attraction (hereafter referred to as "morality frames"); the prevalence and effects of homophobic victimisation (hereafter referred to as "victimisation frames"); the supposed connection between same-sex attraction and HIV/AIDS (hereafter referred to as "AIDS frames"); the role of gender norms in forming attitudes towards same-sex attraction (hereafter referred to as "gender frames"); the importance (or lack thereof) of equality (hereafter referred to as "equality frames"); the legalisation of gay marriage (hereafter referred to as "marriage frames"); the compatibility (or lack thereof) with African culture (hereafter referred to as "UnAfrican frames"); the legalisation of gay adoption and parenting (hereafter referred to as "parenting frames"); and the naturalness (or lack thereof) of same-sex attraction (hereafter referred to as "nature frames"). Table 1 orders the frames mentioned above from the most commonly to least commonly implemented, and represents the distribution of pro-gay sentiments, anti-gay sentiments and neutrality in each of the frames. 
Table 1: Distribution of framing in both corpora

\begin{tabular}{|c|c|c|c|c|c|c|c|}
\hline Frame & Source & $\begin{array}{c}\text { No. of } \\
\text { uses }\end{array}$ & $\begin{array}{c}\text { \% of } \\
\text { corpus }\end{array}$ & $\begin{array}{l}\text { Tol. } \\
\text { uses }\end{array}$ & $\begin{array}{c}\text { Intol. } \\
\text { uses }\end{array}$ & $\begin{array}{l}\text { Neutral } \\
\text { uses }\end{array}$ & Primarily \\
\hline \multirow{2}{*}{ (In)tolerance } & $\mathrm{CP}$ & 135 & $58 \%$ & $48 \%$ & $36 \%$ & $16 \%$ & Pro-gay \\
\hline & $\mathrm{MG}$ & 341 & $62 \%$ & $82 \%$ & $7 \%$ & $11 \%$ & Pro-gay \\
\hline \multirow{2}{*}{ Liberation } & $\mathrm{CP}$ & 77 & $33 \%$ & $58 \%$ & $28 \%$ & $14 \%$ & Pro-gay \\
\hline & $\mathrm{MG}$ & 160 & $29 \%$ & $91 \%$ & $3 \%$ & $6 \%$ & Pro-gay \\
\hline \multirow{2}{*}{ Religion } & $\mathrm{CP}$ & 67 & $29 \%$ & $39 \%$ & $47 \%$ & $14 \%$ & Anti-gay \\
\hline & MG & 154 & $28 \%$ & $74 \%$ & $12 \%$ & $14 \%$ & Pro-gay \\
\hline \multirow{2}{*}{ Rights } & $\mathrm{CP}$ & 67 & $29 \%$ & $57 \%$ & $25 \%$ & $18 \%$ & Pro-gay \\
\hline & $\mathrm{MG}$ & 154 & $28 \%$ & $89 \%$ & $5 \%$ & $6 \%$ & Pro-gay \\
\hline \multirow{2}{*}{ Legal } & $\mathrm{CP}$ & 39 & $17 \%$ & $20 \%$ & $43 \%$ & $37 \%$ & Anti-gay \\
\hline & MG & 182 & $33 \%$ & $78 \%$ & $7 \%$ & $15 \%$ & Pro-gay \\
\hline \multirow{2}{*}{ Morality } & $\mathrm{CP}$ & 53 & $23 \%$ & $30 \%$ & $56 \%$ & $14 \%$ & Anti-gay \\
\hline & MG & 132 & $24 \%$ & $73 \%$ & $15 \%$ & $12 \%$ & Pro-gay \\
\hline \multirow{2}{*}{ Victimisation } & $\mathrm{CP}$ & 32 & $14 \%$ & $66 \%$ & $25 \%$ & $9 \%$ & Pro-gay \\
\hline & MG & 116 & $21 \%$ & $88 \%$ & $1 \%$ & $11 \%$ & Pro-gay \\
\hline \multirow{2}{*}{ AIDS } & $\mathrm{CP}$ & 35 & $15 \%$ & $56 \%$ & $24 \%$ & $20 \%$ & Pro-gay \\
\hline & $\mathrm{MG}$ & 105 & $19 \%$ & $80 \%$ & $8 \%$ & $12 \%$ & Pro-gay \\
\hline \multirow{2}{*}{ Equality } & $\mathrm{CP}$ & 35 & $15 \%$ & $74 \%$ & $12 \%$ & $14 \%$ & Pro-gay \\
\hline & $\mathrm{MG}$ & 83 & $15 \%$ & $86 \%$ & $4 \%$ & $10 \%$ & Pro-gay \\
\hline \multirow{2}{*}{ Marriage } & $\mathrm{CP}$ & 35 & $15 \%$ & $40 \%$ & $34 \%$ & $26 \%$ & Pro-gay \\
\hline & $\mathrm{MG}$ & 83 & $15 \%$ & $83 \%$ & $6 \%$ & $11 \%$ & Pro-gay \\
\hline \multirow{2}{*}{ Gender } & $\mathrm{CP}$ & 44 & $19 \%$ & $49 \%$ & $29 \%$ & $22 \%$ & Pro-gay \\
\hline & MG & 72 & $13 \%$ & $81 \%$ & $3 \%$ & $16 \%$ & Pro-gay \\
\hline \multirow{2}{*}{ UnAfrican } & $\mathrm{CP}$ & 28 & $12 \%$ & $46 \%$ & $39 \%$ & $15 \%$ & Pro-gay \\
\hline & MG & 50 & $9 \%$ & $85 \%$ & $5 \%$ & $10 \%$ & Pro-gay \\
\hline \multirow{2}{*}{ Nature } & $\mathrm{CP}$ & 16 & $7 \%$ & $35 \%$ & $59 \%$ & $6 \%$ & Anti-gay \\
\hline & $\mathrm{MG}$ & 33 & $6 \%$ & $77 \%$ & $9 \%$ & $14 \%$ & Pro-gay \\
\hline \multirow{2}{*}{ Parenting } & $\mathrm{CP}$ & 19 & $8 \%$ & $58 \%$ & $16 \%$ & $26 \%$ & Pro-gay \\
\hline & $\mathrm{MG}$ & 28 & $5 \%$ & $94 \%$ & $3 \%$ & $3 \%$ & Pro-gay \\
\hline
\end{tabular}

The data indicates that the frames that were typically used to express pro-gay sentiments in both corpora included liberation, rights, victimisation, AIDS and equality, and that the frames that were typically used to express anti-gay sentiments included religion, morality and nature. The data further shows that $58 \%$ of City Press's liberation frames and $91 \%$ of the Mail \& Guardian's liberation frames were used to express pro-gay sentiments; $57 \%$ of City Press's rights frames and $89 \%$ of the Mail \& Guardian's rights frames were used to express pro-gay sentiments; $66 \%$ of City Press's victimisation frames and $88 \%$ of the Mail \& Guardian's victimisation frames were used to express pro-gay sentiments; $56 \%$ of City Press's AIDS frames and 80\% of the Mail \& Guardian's AIDS frames were used to express pro-gay sentiments; and 74\% of City Press's equality frames and 86\% 
of the Mail \& Guardian's equality frames were used to express pro-gay sentiments. Further, the data shows that $47 \%$ of City Press's religion frames and $12 \%$ of the Mail \& Guardian's religion frames were used to express anti-gay sentiments; $56 \%$ of City Press's morality frames and $15 \%$ of the Mail \& Guardian's morality frames were used to express anti-gay sentiments; and $59 \%$ of City Press's nature frames and 9\% of the Mail \& Guardian's nature frames were used to express antigay sentiments.

The finding that AIDS frames were primarily used to express pro-gay sentiments in both corpora contradicts the literature, which predicts that AIDS frames are more likely to be used to express anti-gay sentiments. Further, the Mail \& Guardian data demonstrates a pattern in which religion frames are primarily used to express pro-gay sentiments $(74 \%$ of total publications in which religion is topicalised), which again contradicts the literature as it predicts that religious frames are more likely to be used to express anti-gay sentiments. Finally, the data shows that the issues of parenting, gender, marriage and (in)tolerance were primarily topicalised in pro-gay ways in both corpora, which conflicts with claims that "family values" are typically cited to express anti-gay sentiments.

\subsubsection{Commonly used pro-gay frames}

A review of the implementation of pro-gay frames over time shows that the two corpora made use of different pro-gay frames at different times, with both corpora implementing liberation frames, rights frames and victimisation frames in the expression of pro-gay sentiments, and the Mail \& Guardian additionally implementing legal frames and religion frames. The data indicates that liberation frames were the most commonly implemented pro-gay frames throughout the data collection period in both corpora, and showed similar increases in frequency between 2001 and 2006, during which 34\% of City Press's liberation frames were implemented, of which $31 \%$ were used to express pro-gay sentiments and $69 \%$ were used to express anti-gay sentiments, and during which $33 \%$ of the Mail \& Guardian's liberation frames were implemented, of which $92 \%$ were used to express pro-gay sentiments and $4 \%$ were used to express anti-gay sentiments. Further, a statistical analysis of the liberation frames of both corpora showed that $80 \%$ of City Press's and $38 \%$ of the Mail \& Guardian's liberation frames were used in conjunction with rights frames, and that $43 \%$ of City Press's and $23 \%$ of the Mail \& Guardian's liberation frames were used in conjunction with equality frames.

After liberation frames, rights frames were the second most commonly implemented pro-gay frame for the duration of the data collection period in the City Press corpus, showing an increase in frequency between 2003 and 2006, during which 35\% of the corpus' rights frames were implemented, of which $47 \%$ were used to express pro-gay sentiments and $53 \%$ were used to express anti-gay sentiments. After rights frames, victimisation frames were the third most commonly implemented pro-gay frame in the City Press corpus. The frame is used in $14 \%$ of the corpus, of which $66 \%$ were used to express pro-gay sentiments and $25 \%$ were used to express anti-gay sentiments. Following the liberation frame, the legal frame was the second most commonly implemented pro-gay frame in the Mail \& Guardian corpus, and the second most commonly implemented pro-gay frame from 1996 to 1998, during which 16\% of the Mail \& Guardian's legal frames were implemented, of which $80 \%$ were used to express pro-gay sentiments and $7 \%$ were used to express anti-gay sentiments. The rights frame was the third most commonly implemented pro-gay frame in this corpus, and the second most commonly implemented pro-gay frame from the beginning of the data collection period to 1996, increasing 
in frequency in 2006, during which $14 \%$ of the corpus' rights frames were implemented, of which $91 \%$ were used to express pro-gay sentiments and 9\% were used to express anti-gay sentiments. Following the rights frame, the religion frame was the fourth most commonly implemented pro-gay frame and the second most implemented pro-gay frame in the Mail \& Guardian corpus between 2001 and 2006, during which $60 \%$ of the corpus' religion frames were implemented, of which $76 \%$ were used to express pro-gay sentiments and $15 \%$ were used to express anti-gay sentiments. Following this, the victimisation frame was the fifth most commonly implemented pro-gay frame and the second most commonly implemented pro-gay frame from 1998 to 2000, during which $19 \%$ of the Mail \& Guardian's victimisation frames were implemented, of which $86 \%$ were used to express pro-gay sentiments and none were used to express anti-gay sentiments.

A statistical analysis of the pro-gay data demonstrates a strong statistical dependency between pro-gay publications and those implementing equality frames in both corpora, and a medium statistical dependency between pro-gay publications and those implementing liberation frames, rights frames and victimisation frames in the City Press corpus, and a strong statistical dependency between pro-gay publications and those implementing liberation frames, rights frames, victimisation frames, legal frames and religion frames in the Mail \& Guardian corpus. While all of these frames were also used to express anti-gay sentiments in both corpora, these statistical dependencies are useful in determining the extent to which specific frames were implemented as collective action frames by social movement actors.

\subsubsection{Commonly used anti-gay frames}

A review of the implementation of anti-gay frames over time reveals that different frames are foregrounded at different points in the data collection period, with morality frames being the most commonly implemented anti-gay frames from the start of the data collection period until the year 2000 in both corpora, increasing in frequency from 2001 to 2005 in the City Press corpus. During this time $25 \%$ of the corpus' morality frames were implemented, of which $38 \%$ were used to express anti-gay sentiments and $15 \%$ were used to express pro-gay sentiments. In $2006,9 \%$ of the corpus' morality frames were implemented, of which $60 \%$ were used to express anti-gay sentiments and $20 \%$ were used to express pro-gay sentiments. The Mail \& Guardian corpus shows similar implementation patterns from 2001 to 2005 , during which $27 \%$ of the corpus' morality frames were implemented, and in 2006, during which $11 \%$ of the corpus' morality frames were implemented. These frames were primarily used to express tolerant sentiments in the Mail \& Guardian corpus, with $86 \%$ of the morality frames that were implemented between 2001 and 2006 being used to express pro-gay sentiments and $9 \%$ being used to express anti-gay sentiments, and $64 \%$ of the morality frames that were implemented in 2006 being used to express pro-gay sentiments and $21 \%$ being used to express anti-gay sentiments.

Following this, religion frames were the most commonly implemented anti-gay frames from the year 2000 until the end of the data collection period in 2006 for both corpora, increasing in frequency between 2001 and 2006, during which 49\% of City Press's and 60\% of the Mail \& Guardian's religion frames were implemented, largely in response to the debate about the legalisation of same-sex marriage. Similar to the morality frames, City Press primarily implemented religion frames to express anti-gay sentiments, with $27 \%$ of the religion frames that were implemented in City Press between 2001 and 2006 being used to express pro-gay 
sentiments and $55 \%$ being used to express anti-gay sentiments, and $76 \%$ of the religion frames that were implemented in the Mail \& Guardian between 2001 and 2006 being used to express pro-gay sentiments and $27 \%$ being used to express anti-gay sentiments.

Following religion frames, nature frames were the third most commonly implemented anti-gay frame, remaining relatively steady in both corpora. Similar to morality frames and religion frames, City Press primarily used nature frames to express anti-gay sentiments, with $35 \%$ of the corpus' nature frames being used to express pro-gay sentiments and $59 \%$ being used to express anti-gay sentiments, while the Mail \& Guardian primarily implemented nature frames to express pro-gay sentiments, with $77 \%$ of the corpus' nature frames being used to express pro-gay sentiments and $9 \%$ being used to express anti-gay sentiments.

A statistical analysis of the anti-gay data demonstrates a medium statistical dependency between anti-gay publications and those implementing religious frames and moral frames, and a strong statistical dependency between anti-gay publications and those implementing nature frames in the City Press corpus, which means that publications that frame same-sex attraction in terms of religion, morality and nature are more likely to express anti-gay sentiments than other publications in the corpus. By contrast, the data reveals a negative statistical dependency between anti-gay publications and those implementing religion, moral and nature frames in the Mail \& Guardian corpus, which means that publications that frame same-sex attraction in terms of religion, morality and nature are no more likely to express anti-gay sentiments than other publications in the corpus. Finally, the data demonstrates a very strong statistical dependency between religious frames and morality frames in both corpora, which means that a publication topicalising religion is far more likely to mention morality than any other publication in the corpus.

\subsubsection{Commonly used issue frames}

In addition to identifying commonly used anti- and pro-gay frames, the quantitative analysis of the data identified four frames that are widely implemented in both corpora in ways that place certain facets of same-sex attraction on the public agenda, namely (in)tolerance, marriage, gender and parenting. As indicated in Table 1, (in)tolerance is the most widely implemented frame in both corpora, remaining steady throughout the data collection period in the Mail \& Guardian corpus, with $82 \%$ of the (in)tolerance frames being used to express pro-gay sentiments and $7 \%$ being used to express anti-gay sentiments. This issue frame increased in frequency between 2000 and 2006 in City Press, during which 46\% of the corpus' (in)tolerance frames were implemented. Of these, $18 \%$ were used to express pro-gay sentiments and $19 \%$ were used to express anti-gay sentiments.

Following (in)tolerance, the second most widely implemented issue frame was marriage, which increased in frequency between 2001 and 2006. During this period, 71\% of City Press's marriage frames were implemented, of which $36 \%$ were used to express pro-gay sentiments and $44 \%$ were used to express anti-gay sentiments. During the same time, $75 \%$ of the Mail \& Guardian's marriage frames were implemented, of which $85 \%$ were used to express pro-gay sentiments and $7 \%$ were used to express anti-gay sentiments.

After marriage, the third most widely implemented issue frame was gender, which had a relatively low frequency in the first decade of data collection in the Mail \& Guardian, but 
increased in frequency between 1998 and 2006. During this period, 50\% of City Press's gender frames were implemented, of which $43 \%$ were used to express pro-gay sentiments and $35 \%$ were used to express anti-gay sentiments. During the same time, $70 \%$ of the Mail \& Guardian's gender frames were implemented, of which $80 \%$ were used to express pro-gay sentiments and $4 \%$ were used to express anti-gay sentiments.

Finally, parenting was the fourth most widely implemented issue frame, increasing in frequency between 2000 and 2006. During this period, 47\% of City Press's parenting frames were implemented, of which $44 \%$ were used to express pro-gay sentiments and $22 \%$ were used to express anti-gay sentiments. During the same time, $46 \%$ of the Mail \& Guardian's parenting frames were implemented, of which $100 \%$ were used to express pro-gay sentiments.

\subsection{The use of a single frame for opposing arguments}

One of the most noteworthy findings of the analysis is the evidence for how extensively the same frame is used either in support of or in countering arguments for recognising gay rights. For example, frames such as religion and AIDS were used in arguments defending the protection of gay rights as well as in arguments that would deny gay rights. Table 1 shows that AIDS frames were used in 15\% of the City Press corpus, of which 56\% were employed in pro-gay arguments and $24 \%$ for anti-gay arguments. Additionally, the quantitative analysis of the Mail \& Guardian data revealed that AIDS frames were used in $19 \%$ of the corpus, of which $80 \%$ were used in progay arguments and $8 \%$ were used in anti-gay arguments. Notably though, in both publications the use of this frame was weighted towards the pro-gay arguments.

An analysis of the implementation of AIDS frames over time shows that the two newspapers display similar patterns in their implementation of the frame. Consider Figure 2 below:

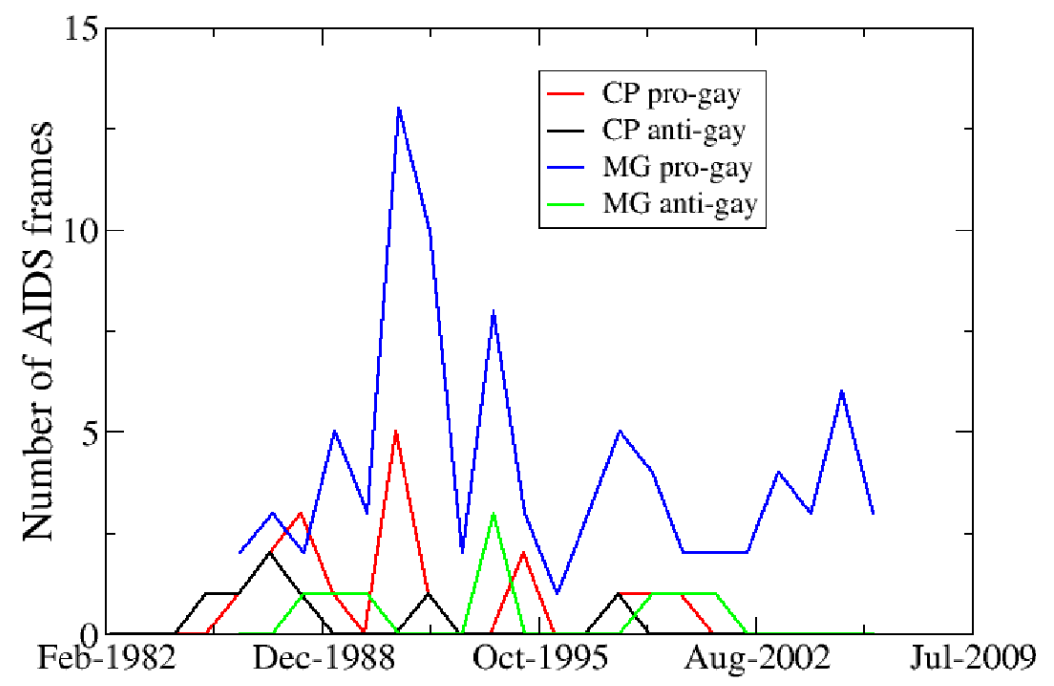

Figure 2. Distribution of pro- and anti-gay AIDS frames in both corpora

Figure 2 shows that the frame was most commonly used in the years between 1985 and 1994 in the City Press corpus, during which $76 \%$ of the newspaper's AIDS frames were implemented. Of these, $58 \%$ were used to express pro-gay sentiments and $23 \%$ were used to express anti-gay sentiments. Further, $21 \%$ of the corpus' AIDS frames were implemented 
between 1995 and 2000, of which 71\% were used to express pro-gay sentiments and 14\% were used to express anti-gay sentiments. Similarly, Figure 2 shows that $53 \%$ of the Mail \& Guardian's AIDS frames were implemented between 1982 and 1994, of which 80\% were used to express pro-gay sentiments and $7 \%$ were used to express anti-gay sentiments. Further, $24 \%$ of the corpus' AIDS frames were implemented between 1995 and 2000, of which 50\% were used to express pro-gay sentiments and $15 \%$ were used to express anti-gay sentiments, and $22 \%$ of the corpus' AIDS frames were implemented between 2001 and 2006, of which $92 \%$ were used to express pro-gay sentiments and $4 \%$ were used to express anti-gay sentiments. The time period in which AIDS frames were most frequently implemented in both corpora coincides with the period during which the media introduced the public to the phenomenon of AIDS and attempted to educate readers on the differences between Western homosexual patterns of transmission and African heterosexual patterns of transmission. The plateau and eventual decline of City Press publications and anti-gay Mail \& Guardian publications that frame samesex attraction in terms of AIDS marks the point at which the newspapers stopped implying causation between homosexuality and AIDS.

Similar to the AIDS frames, religion frames were implemented frequently in both pro- and antigay arguments. Table 1 shows that religion frames were used in $29 \%$ of the City Press corpus, of which $39 \%$ were used to express pro-gay sentiments and $47 \%$ were used to express anti-gay sentiments, and that religion frames were used in $28 \%$ of the Mail \& Guardian corpus, of which $74 \%$ were used in pro-gay arguments and $12 \%$ were used in anti-gay arguments. Thus, unlike the AIDS frame discussed above, the two newspapers show different patterns in their implementation of the religion frame, with City Press using the frame to express anti-gay sentiments more frequently than pro-gay ones, and the Mail \& Guardian using the frame to express pro-gay sentiments more frequently than anti-gay ones.

An analysis of the implementation of religion frames over time shows that the two newspapers display similar patterns. Consider Figure 3 below:

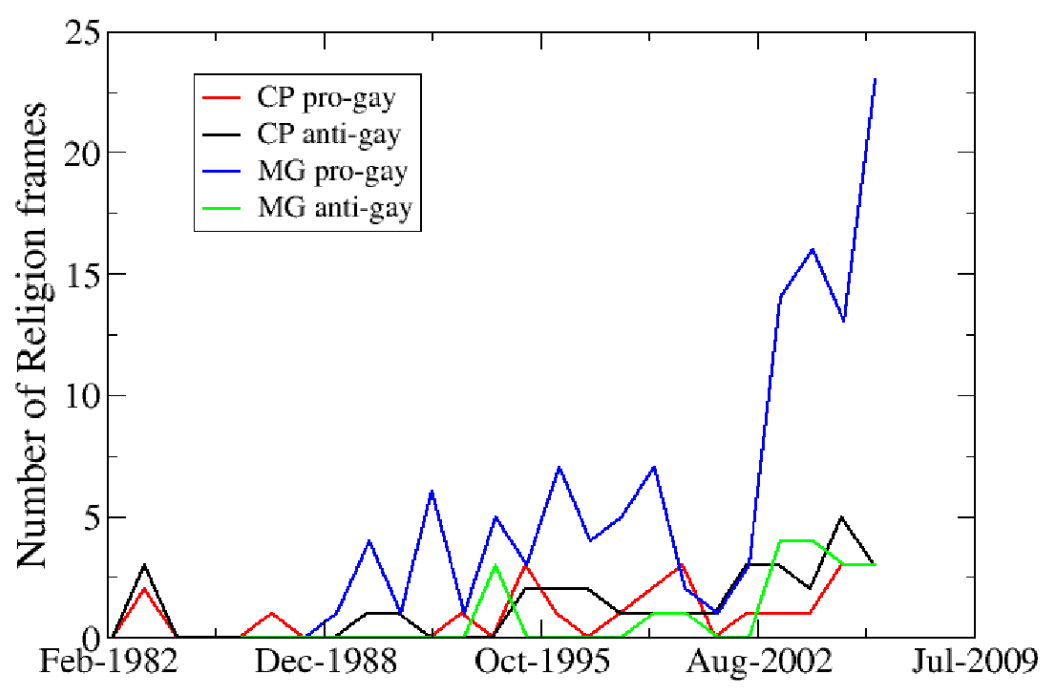

Figure 3. Distribution of pro- and anti-gay religion frames in both corpora

Figure 3 shows that the religion frame was most commonly used in the years between 2001 and 2006, during which 49\% of City Press's religion frames were implemented. Pro-gay sentiments 
were expressed by $27 \%$ of these religion frames and $54 \%$ were used to express anti-gay sentiments. During the same time, $61 \%$ of the Mail \& Guardian's religion frames were implemented, of which $76 \%$ were used to express pro-gay sentiments and $15 \%$ were used to express anti-gay sentiments. Interestingly, religion frames were the most frequently implemented anti-gay and pro-gay frames in the Mail \& Guardian during these last five years of data collection, which is evidence of the fact that religious discourses centring on same-sex attraction were increasingly placed on the public agenda during these transitional times (which included the legalisation of gay marriage and adoption) as well as being evidence of the extent to which the original anti-gay religion frames were counterframed as a pro-gay argument.

While the finding that the same frame was often used in both pro- and anti-gay arguments limits the extent to which certain frames can be labelled "pro-gay" or "anti-gay", it does shed light on the process of counterframing, through which social constructs are reframed by using the same frame implemented by opponents of the social movement with the goal of providing alternative perspectives. Further, the frequency at which particular frames are implemented to express particular sentiments allows these findings to disclose which ideological stances underlie arguments for and against gay rights. This allows one to categorise such arguments in terms of the likelihood of them being used by particular religious and political in-groups and out-groups, and the ways in which they should be countered.

\section{Discussion}

The distribution of pro-and anti-gay publications indicates that in the observed period overall the Mail \& Guardian considered issues relating to same-sex attraction to be more newsworthy than did City Press. One can therefore conclude that the Mail \& Guardian placed same-sex attraction on the public agenda more decidedly than City Press. The pattern in which both corpora published gay-related material at the highest frequency during the last five years of the data collection period coincides with the time in which same-sex attraction was increasingly framed in terms of marriage and parenting. This followed the period in which basic rights had been established, as is illustrated in the decriminalisation of sodomy (1998) and the awarding of immigration rights and shared pension benefits to same-sex couples (1999). This indicates that socio-political and legal developments contributed to the extent to which same-sex attraction was placed on the public agenda in the media.

The analysis of the implementation of pro-gay frames shows that the two newspapers made similar use of liberation frames, rights frames and victimisation frames in pro-gay publications, although both liberation frames and rights frames were used more commonly to express antigay sentiments than pro-gay sentiments in the City Press corpus. Further, the Mail \& Guardian also made frequent use of legal frames, religion frames and AIDS frames in articulating progay sentiments, frequently emphasising the legal troubles faced by LGBT citizens and the inaccuracy of stereotypes that construct gay men as predominant carriers of AIDS, and counterframing anti-gay religious arguments. Although an analysis of the implementation of anti-gay frames shows that the two newspapers have similar framing patterns, with both corpora implementing religion frames, morality frames and nature frames in publications containing anti-gay sentiments, the data indicates that City Press used these anti-gay frames far more frequently than the Mail \& Guardian, and that the Mail \& Guardian primarily used these frames to express pro-gay sentiments. Finally, the data indicates that the abovementioned frames were implemented more frequently at certain points in the data collection period than others, with 
AIDS frames being implemented most frequently between 1990 and 1992 in both corpora, and religion frames being implemented most frequently between 2001 and 2006 in both corpora.

As discussed above, the frames that were typically used to topicalise specific facets of LGBT life included (in)tolerance, marriage, gender and parenting. While all four of these issue frames were primarily used in conjunction with the expression of pro-gay sentiments, the data indicates that City Press was significantly less pro-gay in its discussion of these issues than the Mail \& Guardian, and that gender and parenting frames were primarily used to express anti-gay sentiments in the time periods during which they were implemented most frequently in the City Press corpus. As is the case with the pro- and anti-gay frames discussed above, the data indicates that the different issue frames were not necessarily implemented at an even frequency throughout the data collection period, with (in)tolerance being topicalised most frequently at the end of the data collection period in the City Press corpus and at the beginning of the data collection period in the Mail \& Guardian corpus, gender remaining relatively stable throughout the data collection period in both corpora, and marriage being topicalised most frequently in the last five years of the data collection period in both corpora. Interestingly, while the data does indicate an increase in the frequency of the implementation of parenting frames towards the end of the data collection period in both corpora, this issue was not topicalised nearly as often as marriage, which demonstrates the fact that not all aspects of the gay liberation movement received equal media attention.

The finding that AIDS frames were primarily used to express pro-gay sentiments in both corpora and the finding that religion frames were primarily used to express pro-gay sentiments in the Mail \& Guardian corpus contradicts the expectations conveyed by much of the literature, which emphasises the role of AIDS and religion in the perpetuation of homophobia, and is largely silent about the potential of realigning such frames in positive ways. These findings indicate that social movement actors that contributed pro-gay sentiments to public discourses topicalising South Africa's gay liberation movement were successful in reframing same-sex attraction in a way that reconstructed the attitudes and values that were typically expressed in public discourse. Further, the distribution of pro- and anti-gay AIDS frames and religion frames shows that the majority of the AIDS counterframing took place in the first 10 years of the data collection period in both corpora, while the majority of the religion counterframing took place during the last five years of the data collection period in both corpora. Finally, the fact that all of the frames identified in the study were implemented in the expression of both pro- and antigay sentiments brings to light the benefits of counterframing anti-gay arguments in terms of the same frame that is used in anti-gay arguments, and the possibility of mobilising potential supporters and demobilising potential opponents by framing pro-gay arguments in ways with which they are familiar.

\section{Conclusion}

The quantitative data reviewed in this article has been presented to provide an illustrative overview of how two South African newspapers with notably different readerships characterised LGBT communities and societal attitudes regarding the rights of such groups. This should shed some light on the thematic and argumentative complexity of the gay liberation discourse of this study. Eventually, from a critical and activist perspective, this approach to the data will also assist in identifying and addressing discourse that denies basic human and citizenship rights to LGBT groups. Arguments against affording such rights are often hidden 
under layers of indirectness, implicature, presupposed meaning, references to various sources of authority, strategic attribution and ideologically-motivated framing. This study intended to shed some light on the processes by which social constructs are framed, reframed and counterframed in public discourses as such insights could aid social movement actors that wish to place their concerns on the public agenda in order to bring about social change. Lastly, although the processes involved in collective action framing could not be discussed in detail here, this study would like to contribute to the movement towards greater interdisciplinarity in research by showing how social theories and methodologies such as Social Movement Theory and CAF can supplement some of the work done in the fields of CDA and Queer Linguistics which all have a common interest in the role of public discourse bringing about social change.

\section{References}

Calzo, J.P. and L.M. Ward. 2009. Media exposure and viewers' attitudes toward homosexuality: Evidence for mainstreaming or resonance? Journal of Broadcasting and Electronic Media 53(2): 280-299.

Chong, D. and J.N. Druckman. 2013. Counterframing effects. The Journal of Politics 75(1): 1-16.

Cilliers, C. 2007. Media and sexual orientation: The portrayal of gays and lesbians. In P.J. Fourie (Ed.) Media studies volume 2: Policy, management and media representation. Cape Town: Juta and Co. pp. 331-358.

Druckman, J.N. 2001. The implications of framing effects for citizen competence. Political Behaviour 23(3): 225-256.

Gamson, W.A. 1995. Constructing social protest. In H. Johnston and B. Klandermans (Eds.) Social movements and culture, Volume 4: Protest and contention. Minneapolis: University of Minnesota Press. pp. 85-106.

Gamson, W.A. 2004. Bystanders, public opinion, and the media. In D.A. Snow, S.A. Soule and H. Kriesi (Eds.) The Blackwell companion to social movements. Oxford: Blackwell Publishers. pp. 242-261.

Gamson, W.A. and G. Wolfsfeld. 1993. Movements and media as interacting systems. Annals of the American Academy of Political and Social Sciences 528: 114-125.

Gevisser, M. 1995. Defiant desire. In E. Cameron and M. Gevisser (Eds.) Defiant desire: Gay and lesbian lives in South Africa. Braamfontein: Ravan Press. pp. 14-88.

Milani, T.M. 2013. Are 'queers' really 'queer'? Language, identity and same-sex desire in a South African online community. Discourse and Society 24(5): 1-19.

Mongie, L.D. 2013. The Discourse of Liberation: The Portrayal of the Gay Liberation Movement in South African News Media from 1982 to 2006. Unpublished PhD thesis, University of Stellenbosch. 
Ndlovu, N. 2006. Out in the media? Knowledge, attitudes and practices of the media towards lesbian, gay, bisexual, transgender and intersex issues and stories. Available online: http://www.gala.co.za/resources/docs/OutInTheMediaFinalReport.pdf. (Accessed 4 May 2015).

Reid, G. and T. Dirsuweit. 2002. Understanding systemic violence: Homophobic attacks in Johannesburg and its surrounds. Urban Forum 13(3): 99-126.

Snow, D.A. and R.D. Benford. 1988. Ideology, frame resonance and participant mobilisation. International Social Movement Research 1: 197-217.

Snow, D.A. and R.D. Benford. 1992. Master frames and cycles of protest. In A.D. Morris and C. McClurg Mueller (Eds.) Frontiers in social movement theory. New Haven: Yale University Press. pp. 133-155.

Snow, D.A. and R.D. Benford. 2000. Framing processes and social movements: An overview and assessment. Annual Review of Sociology 26: 611-639.

Snow, D.A., E. Burke Rochford Jr., S.K. Worden and R.D. Benford. 1986. Frame alignment processes, micromobilisation, and movement participation. American Sociological Review 51(4): 464-481.

Tarrow, S. 1988. National politics and collective action: Recent theory and research in western Europe and the United States. Annual Review of Sociology 14: 421-440.

Van Dijk, T.A. 1991. The interdisciplinary study of news as discourse. In K. Bruhn-Jensen and N. Jankowski (Eds.) Handbook of qualitative methods in mass communication research. London: Routledge. pp. 108-120.

Van Dijk, T.A. 1993. Principles of critical discourse analysis. Discourse and Society 4(2): 249283.

Van Dijk, T.A. 1995. Power and the news media. In D. Paletz (Ed.) Political communication and action. Cresskill, NJ: Hampton Press. pp. 9-36.

Van Dijk, T.A. 1998. Opinions and ideologies in the press. In A. Bell and P. Garrett (Eds.) Approaches to media discourse. Oxford: Blackwell Publishers. pp. 21-63.

Van Dijk, T.A. 2003. Critical discourse analysis. In D. Schiffrin, D. Tannen and H.E. Hamilton (Eds.) The handbook of discourse analysis. Oxford: Blackwell Publishers. pp. 352-371. 